\title{
The Delivery of Business Courses via the African Virtual University: A case study
}

Mark Graber and Susan Bolt

Curtin University of Technology

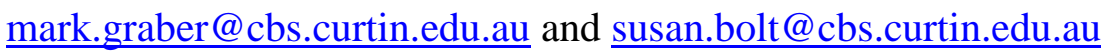

\begin{abstract}
In this case study the delivery of business courses as a result of the partnership between the African Virtual University (AVU) and Curtin University in Western Australia is described. From 2004 to 2008 degree and diploma business courses were delivered using WebCT in the four AVU partner locations: Addis Ababa University (Ethiopia), Kigali Institute of Science \& Technology (Rwanda), Kenyatta University (Kenya), University of Dar es Salaam (Tanzania). In spite of significant hurdles that made delivery of the business courses challenging, 188 students graduated as a result of this initiative. This case study is significant because it describes the outcomes of an AVU Phase 2 initiative.
\end{abstract}




\section{Introduction}

Much has been written about the difficulties of delivering distance education in Sub-Saharan Africa, particularly in relation to the African Virtual University (AVU) (Juma, 2006; Light, 1999; Moyo, 2003; Ondari-Okemwa, 2002). The second phase in the AVU agenda was due to commence in 1999 (Ondari-Okemwa, 2002) but it commenced much later (2002; 2003a, b). In Phase 2, three international partnerships were established to deliver degree and diploma courses: In Australia, the Royal Melbourne Institute of Technology (RMIT) agreed to deliver computer science programs and Curtin University (Curtin) agreed to deliver business courses. In Canada, the Laval University, also, agreed to deliver computer science programs (2003b, Juma, 2006; Kigotho, 2006). For lecturers from Curtin University the roll-out of business education, in partnership with the AVU, commenced in 2004 and was due to be completed in 2007 (2003a). However, the delivery of distance degree and diploma courses was fraught with difficulties; by 2006 RMIT had withdrawn from the partnership because of the AVU's failure to meet its financial commitments and there were plans to finalise the remaining two partnerships (Kigotho, 2006).

Interestingly, very little has been published specifically in relation to the completion of Phase 2. So, this paper has been written to provide information about students' completion of business degree and diploma courses offered through the AVU-Curtin partnership. This case study was developed as a result of research. The project context is described in a review of the literature; its implementation is described in relation to the delivery of course materials and outcomes of the project.

The first author was involved in the delivery of business education in the AVU-Curtin partnership. The second author was not involved in the course delivery but, rather, as a fellow 
researcher. Although, as a participant, the first author contributed significant first-hand knowledge and experience of the course delivery through the AVU-Curtin partnership, the authors minimised bias through triangulation of data. The interpretive approach used to develop this case study involved mixed methods of data collection. Quantitative data concerning student completions were collected from Curtin University's Student One databases and qualitative data about factors affecting the course delivery were collected by interviewing key informants involved in the project. Although different opinions about the success of the project emerged as a result of interviewing key informants, it was found that 167 students enrolled in the AVU graduated with a Bachelor of Business Administration (BBA) and 21 students graduated with a Diploma of Business as a result of this project. Concern for students' educational success was demonstrated in commitment to the project well beyond its initial expected completion date and in spite of any subsequent difficulties.

\section{Background to AVU Distance Education}

Prior to the establishment of the AVU only $3 \%$ of African youth enrolled in a college education. So, it was out of a deep concern for the educational success of African youth that the World Bank launched its virtual university in 1997 (Juma, 2006; Light, 1999; Mbarika, 2003). In stage 1 from 1997-1999, the AVU offered a pilot program in collaboration with the USA, Ireland and Canada. In stage 2, from 1999-2002, 31 learning centres in 17 African countries were established to extend the number of partnerships and provide a range of courses. In stage 3, from 2002-2007, the AVU offices were relocated from Washington to Nairobi and the AVU operated as an independent not-for-profit organisation with the aims of extending facilities and participation (Juma, 2002, 2006; Kigotho, 2006; Mbarika, 2003) 
The AVU can be described as a "university without walls" that uses information and communication technologies to give the countries of Sub-Saharan Africa direct access to high quality academic faculty and learning resources. The objective of AVU is to build capacity and support economic development by leveraging the power of modern telecommunications technology to provide world-class quality education and training programs to students and professionals in Sub-Saharan Africa. The AVU provides students access to an online digital library with over 1,100 full-text journal articles, and more than 10,000 e-mail accounts (2007; Juma, 2002; Mbarika, 2003). When the AVU established the concept of an interactive instructional telecommunications network to deliver distance education in countries with limited use of Internet technologies, it was relatively new and innovative (Mbarika, 2003; Ondari-Okemwa, 2002).

\section{Constraints Impacting on AVU Projects}

Although technology has enhanced distance education in countries like Australia, it has been a hurdle in countries where the 'digital divide' is great (Moussa \& Schware, 1992; Mutula, 2007). In their research, Moussa and Schware (1992) identified five major factors that limit the success of IT projects in Africa; institutional weaknesses, human resources, funding, local environment, and technology and information changes. Thus, projects tended to be poorly planned and had unclear objectives. There were insufficient numbers of trained staff, a high staff turnover rate and lack of awareness about how to use information technology. The cost of projects was typically underestimated. There was a lack of environmental support, limited access to appropriate hardware and software and use of inappropriate policies and procedures (Moussa \& Schware, 1992). 
A decade later Ondari-Okemwa (2002) noted the same constraints were still evident in the AVU partnership in Kenya which was one of the first African nations to connect to the Internet (Mutula, 2001). For example, staff did not trust each other and could not work in teams. There was a lack of staff training and both staff and students had limited IT skills. Electricity supplies fluctuated and interfered with the ability to deliver the AVU courses. In some situations the problems were exacerbated. For example, Tanzania was not as well 'technologically situated' as other countries; according to measurements taken using the Information Society Index Tanzania ranked 165/180 countries (Mutula, 2007). By contrast, even though Kenya was relatively technologically poor, in 1999 it was "one of the top ten countries in Africa as far as Internet connectivity is concerned" (Moyo, 2003; Mutula, 2001; Ondari-Okemwa, 2002).

One of the biggest challenges in delivering distance education has been the lack of access to Internet and infrastructure in Africa. For example, the learning centres, which required efficient and effective communications, often had unreliable and costly Internet connections and telephone services. This put the AVU and partners under pressure, pushing the AVU to invest in infrastructure rather than concentrate on its core business of delivering quality programs. AVU partner institutions experienced difficulty because of limited access to the world-wide-web; low bandwidth; restrictive communication policy; high telecommunications costs; slow Internet connectivity; limited computing resources and infrastructure; limited ICT skills amongst participants; and resistance to change (Juma, 2002; Moyo, 2003).

The extent of the difficulties experienced by AVU partners because of the above mentioned limitations is highlighted in the findings of recent research into e-learning across Africa. In 2007, Unwin surveyed "e-learning users and advocates in 42 African countries" and found 
that although respondents were enthusiastic about e-learning in Africa there were diverse practices and "the use of computers for learning was still in its infancy" (Unwin, Kleeson, Hollow, Williams, Oloo, Alwala, Mutimucuio, Eduardo, \& Muianga, 2010, p.6). More recently Unwin, et al. (2010) surveyed a broader cross section of key stakeholders in the overall learning environment of Africa, more specifically, regarding the usage of learning management systems (LMS). Typically, the problems identified in previous decades still prevailed; there were constraints due to high costs, poor infrastructure and power failures, slow Internet speed and low bandwidth, limited resources and lack of knowledge and skills (Unwin, et al., 2010). In the survey conducted by Unwin, et al. (2010) 49\% ( $n=174)$ of respondents claimed they had used an LMS in the last year for teaching purposes; $73 \%$ of respondents who used the LMS for teaching used Blackboard $(n=74)$, Moodle $(n=58)$ or WebCT ( $n=43)$. Even though these results appear to indicate considerable LMS usage the actual frequency of usage was relatively low; " $46 \%$ of respondents who ... used LMSs for teaching claimed they uploaded material less frequently than once a month and only $9 \%$ claimed to do so on a daily basis" (Unwin, et al., 2010, p.13).

Given this history of difficulty associated with delivering distance education in Africa it would be expected that the AVU-Curtin partnership would, also, experience similar difficulties and the delivery of business courses would be affected.

\section{Participating Institutions in the AVU-Curtin Partnership}

In a 'note to staff' on $23^{\text {rd }}$ May, 2002 the then Vice-Chancellor announced that Curtin was the preferred tender for the \$4(AUD) million AVU initiative. The project was to run over a threeyear period with Addis Ababa University in Ethiopia as the leading partner institution in conjunction with the AVU office in Nairobi. The other AVU partner institutes were Kigali 
Institute of Science \& Technology in Rwanda, Kenyatta University in Kenya, and the University of Dar es Salaam in Tanzania. Curtin Business School (CBS) would provide a business degree course (BBA) in the AVU context and Curtin Kalgoorlie's Vocational Training and Education Centre (VTEC) would provide a business diploma course (2002).

\section{Delivery of Business Courses in the AVU-Curtin Partnership}

The typical AVU classroom had between 25-30 students, sitting at their desks watching broadcasts on large-screen projectors, television monitors or computers. During the class, students had the opportunity for real-time interaction with instructors using phone lines or email. This framework allowed students in Rwanda, for example, to pose a question to lecturers in Perth that could be heard and commented upon by students in Kenya and Ethiopia. At each participating AVU learning centre, on-site moderators guided students through the materials and liaised with course instructors. The AVU IT infrastructure is described in the following paragraphs and in Figure 1.

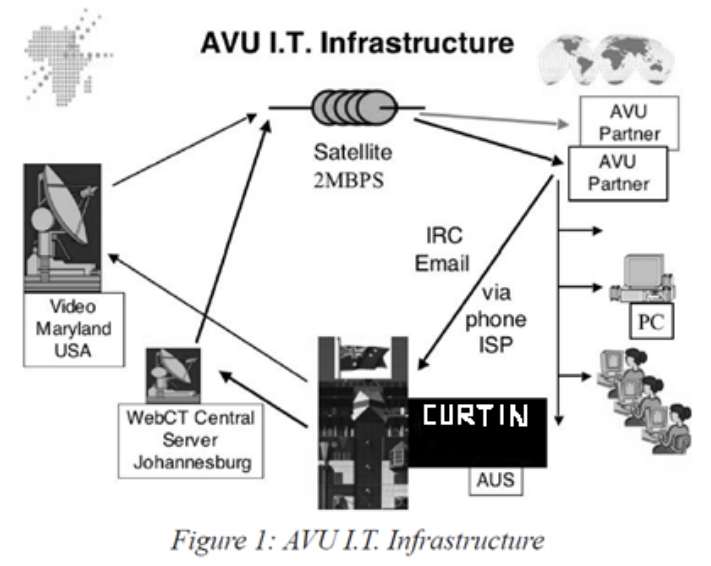

Initially the central WebCT Campus Edition 3.7 server was located in Johannesburg, South Africa which broadcasted Internet packets to the four partner universities via satellite.

However, in the early stages of the partnership this arrangement was changed and courses 
were transmitted to AVU's central uplink facilities in Maryland and then beamed via satellite to the AVU learning centres. The satellite link was only one-way, central to local. Two-way satellite transmission was planned; however, due to the unreliable satellite connection prerecorded videos were often posted to the four university partners.

Student PC workstations at each local site transmitted Internet packets via intranet, phone line and an ISP. Bandwidth in the local to central direction could vary between 28.8KBPS and 64KBPS. Each university partner had a WebCT Campus Edition 3.7 server installed with copies of learning materials from WebCT central in Johannesburg/Maryland. Synchronising material on the central and local WebCT servers was completed via a manual upload process. Students accessed WebCT learning materials and news forums via learning centres attached to each university.

Each WebCT server provided news or discussion forums for each course. The central WebCT server provided one forum for staff only and another for staff and students from all sites. Each local WebCT server provided the same forums, but tailored to suit local needs. These discussion forums not only reduced the need for individual emails, but also provided material for a Frequently Asked Questions (FAQ) bulletin board. FAQs were carried over between delivery cycles whereas discussion forums were emptied at the start of each delivery cycle.

The central WebCT discussion forum was the main medium for electronic queries. The learning facilitators responded to queries from students from all sites. Students were strongly encouraged to assist each other, reinforcing a student-centred learning approach. Curtin University course coordinators responded to queries and monitored progress of facilitators and students. Assignments were submitted via central WebCT; hence, administration and 
moderation of the overall assessment process was less fragmented. This made all student results accessible to all facilitators and unit coordinators.

Issues of access to technology within AVU partners still remained. There were insufficient numbers of workstations available, electricity supplies were inconsistent. The implementation of uninterruptible power supply (UPS) machines for backup reduced downtime. During initial visits CBS managers were shown facilities and resources that appeared adequate but by the commencement of the course, facility allocation had changed. For example, due to RMIT also winning a tender with the AVU, there were more students enrolled in courses than could be catered for by the existing facilities and equipment.

\section{Discussion of Research Methodology and Project Outcomes}

The implementation of the AVU-Curtin partnership in relation to the delivery of the business courses was described in the previous section. A further aim of this research was to describe the outcomes of the project. In this section the research methodology and outcomes of the project are described. As there were only a small number of people involved in the project four key informants were purposively selected and interviewed; two participants were project managers and two were lecturers. In addition, records of AVU students' enrolments and course completions were accessed from Curtin's Student One database. Table 1 below shows that 350 students enrolled in degree and diploma courses delivered through this project in the four locations from 2004 to 2008. Further information about student completions is shown later in the paper.

(INSERT TABLE 1) 
The total number of student enrolments, shown in Table 1, were derived from an analysis of eight Excel spreadsheets of data that provided details about students' enrolment status, the year in which they first enrolled, the name of the partner institution in which they were enrolled and the name of the course in which they were enrolled. The researchers tallied the data recorded in nine categories of student enrolment status, over the four partner institutions and two courses which spanned a five year period. The results were aggregated and reported as a table to provide an indication of the overall student enrolment in this project.

A further Excel spreadsheet identified students graduating with a Bachelor of Business Administration (BBA) by indicating the year and date of their graduation and the locations of the partner institutions in which they were enrolled. The three-year degree course was offered for students to enrol in 2004 and 2005; students would have graduated from this course in 2006 and 2007. However, there were no graduations in 2006 and students were still graduating from this course as late as in 2009. The extended timeframe with regard to completion of the course enhanced students' opportunities to graduate with a BBA. In 20072008 existing students were offered the chance to transfer to a diploma course; a further 21 students graduated as a result of changing to the alternative course. Table 2 shows the locations and numbers of students who graduated with either a BBA or diploma 2007-2009. In addition to this the major outcomes of students - passing the course, being absent without leave or being terminated from the course are shown as percentages in Table 2. Students who withdrew from courses or encountered administrative difficulties with their enrolment have not been included in any of the data presented in this paper.

(INSERT TABLE 2)

Indeed, there were many hurdles to students' successful completion of these business courses. For example, during the implementation of this program some students were under the threat 
of death by the militia. Also, as in the previously cited example of RMIT (Kigotho, 2006), Curtin University experienced difficulty receiving payment from the AVU. Curtin University staff had to act flexibly in such dynamic circumstances to do what could be done to help students complete the courses. It is difficult to estimate the cost of each graduation in financial or human terms. In the following section, further findings in relation to the resourcing of this venture are described as a result of interviews with key stakeholders.

Interviewees were asked seven questions in total. In this paper, the focus is on participants' responses to three of those questions:

1. From your perspective, what were any issues that arose during the project?

2. How did the people in the AVU-Curtin partnership resolve issues of access to relevant information and communication technologies?

3. What success factors, in your opinion, are critical to distance learning?

Although the four interviewees had differing perspectives, the most prominent theme that emerged was in relation to resources - human, curriculum, and time, financial and operational resources. The project was resource intense and more operational people were needed to support the project. There were too few resources for the number of students involved; for example, there were not enough computers for students. It took a lot of time to develop curriculum resources; once developed the use of curriculum resources was not maximised. There were differing expectations and understandings about the terms of contracts, roles and delivery of courses. Changes in personnel, strikes and technological difficulties further complicated the situation. 
With regard to the delivery of distance education, access to information and communications technologies was a particular issue that participants had to resolve. Whereas the initial intention was to transmit lectures via satellite, Government regulations in Ethiopia resulted in the need to video lectures at short notice. Initially, videos were made and posted to the AVU server in Johannesburg to be beamed via satellite to the various locations. Later, the AVU server was re-located to Maryland and subsequently to Nairobi. Videos, CDs and DVDs were all used and students were encouraged to use hard copies because access to digital resources was limited.

The three main themes that emerged from the interviews in relation to factors critical to the success of distance learning were: clear goals, flexible delivery and resourcing. All partners and participants in distance education projects such as this need to have clear and agreed understandings about roles, and the purposes and parameters of the project. The capacity to provide flexible course delivery is linked to resourcing. For example, there was a need for more suitably skilled staff, hardware, software and infrastructure to be provided.

\section{Conclusion}

In this paper the implementation and outcomes of the AVU-Curtin partnership in which business degree and diploma courses were delivered have been described. The information presented in this paper was founded in a review of the literature and case study research. The experiences described by Curtin respondents were consistent with the literature; the same challenges facing the delivery of distance education courses in Africa prevailed. The data presented in this paper refers specifically to the courses offered through Curtin Business School; it does not refer to any experiences or data in relation to the Curtin Kalgoorlie Vocational and Training and Education Centre. Moreover, perspectives of AVU partners and 
students were not included in this research. In future, further research could investigate these other scenarios. The key message presented in this paper is that in spite of the 'traditional' hardships of delivering distance education in Africa the course has been completed and as a result 188 students now possess business qualifications they may not have received without the efforts of all concerned with this aspect of the Phase 2 AVU initiative. 


\section{References}

(2002) Office of the Vice-Chancellor; Note to Staff 23 May 2002 - African Virtual University (AVU).

(2003a) African Virtual University wins Australian cash, IT Training, 09547940.

(2003b) Australia launches degree courses in Africa, African Business, 283, 27.

(2007) African Virtual University: About -Background, Accessed 11 February, 2009 from http://www.avu.org/inner.asp?active page id=|233|227|130|224|36|81|133|59| $\underline{235|230| 57|25| 59|137| 130|247| 199|247| 88|2| 5|229| 230|84| 33|195| 250|204| 23}$

\section{$\underline{6|221| 65|94| 229|226| 32|14| 138|216| 97|96| 118}$}

Juma, M.N. (2002) The impact of implications of open courseware for higher education in developing countries: The case of the African Virtual University (AVU), Presented to UNESCO Forum on Open Courseware, 1-3 July, 2002, Paris.

Juma, M.N. (2006) Kenyatta University - African Virtual University, In S. D’Antonio (Ed.), The virtual university models and messages. (UNESCO).

Kigotho, W. (2006) Facing financial difficulties, African Virtual U. revamps itself, The Chronicle of Higher Education, 53(17), pp. 44-46.

Light, D.A. (1999) Pioneering distance education in Africa, Harvard Business Review, 77(5), p. 26.

Mbarika, V.W.A. (2003) Approaching Sub-Saharan Africa's educational dilemma with teleeducation, IEEE Technology and Society Magazine, (Winter 2003/2004), pp. 20-26.

Moussa, A. \& Schware, R. (1992) Informatics in Africa space: Lessons from World Bank experience, World Development, 20(12), pp. 1737-1752.

Moyo, S. (2003) Distance learning and virtual education for higher education in Africa: Evaluation of options and strategies, African and Asian Studies, 2(4), pp. 497-521. 
Mutula, S.M. (2001) The IT environment in Kenya: Implications for libraries in public universities, Library Hi Tech, 19(2), pp. 155-166.

Mutula, S.M. (2007) Digital divide and economic development: A case study of Sub-Saharan Africa, The Electronic Library, 26(4), pp. 468-489.

Ondari-Okemwa, E. (2002) Challenges of harnessing virtual information resources in Kenya: The case of the African Virtual University, Journal of Information Science, 28(4), pp. 321-329.

Unwin, T., Kleessen, B., Hollow, D., Williams, J.B., Oloo, L.M., Alwala, J., Mutimucuio, I., Eduardo, F., \& Muianga, X. (2010) Digital learning management systems in Africa: Myths and realities, Open Learning: The Journal of Open and Distance Learning, 25(1), pp.5-23. 


\begin{tabular}{|l|l|c|c|c|c|}
\hline University & Course & $\mathbf{2 0 0 4}$ & $\mathbf{2 0 0 5}$ & $\mathbf{2 0 0 7}$ & $\mathbf{2 0 0 8}$ \\
\hline \multirow{2}{*}{$\begin{array}{l}\text { Addis Ababa } \\
\text { University }\end{array}$} & Degree & 71 & 107 & 0 & 0 \\
\cline { 2 - 6 } & Diploma & 0 & 0 & 15 & 0 \\
\hline \multirow{2}{*}{ Kenyatta University } & Degree & 14 & 22 & 0 & 0 \\
\cline { 2 - 6 } & Diploma & 0 & 0 & 0 & 1 \\
\hline \multirow{2}{*}{ University of Dar es Salaam } & Degree & 15 & 10 & 0 & 0 \\
\cline { 2 - 6 } & Diploma & 0 & 0 & 1 & 0 \\
\hline \multirow{2}{*}{$\begin{array}{l}\text { Kigali Institute of Science \& } \\
\text { Technology }\end{array}$} & Degree & 40 & 49 & 0 & 0 \\
\cline { 2 - 6 } & Diploma & 0 & 0 & 3 & 2 \\
\hline
\end{tabular}

Table 1: Numbers of Student enrolled in AVU-Curtin Bachelor of Business Administration Degree and Diploma Courses 


\begin{tabular}{|l|l|c|c|c|c|c|c|}
\hline University & Course & $\mathbf{2 0 0 7}$ & $\mathbf{2 0 0 8}$ & $\mathbf{2 0 0 9}$ & PASS & AWOL & TERM \\
\hline $\begin{array}{l}\text { Addis Ababa } \\
\text { University - Ethiopia }\end{array}$ & Degree & 41 & 45 & 1 & $50 \%$ & $37 \%$ & $13 \%$ \\
\cline { 2 - 9 } & Diploma & 15 & 0 & 0 & $100 \%$ & $0 \%$ & $0 \%$ \\
\hline \multirow{2}{*}{$\begin{array}{l}\text { Kenyatta University - } \\
\text { Kenya }\end{array}$} & Degree & 11 & 10 & 0 & $57 \%$ & $43 \%$ & $0 \%$ \\
\cline { 2 - 9 } $\begin{array}{l}\text { University of Dar es Salaam } \\
\text { - Tanzania }\end{array}$ & Diploma & 0 & 1 & 0 & $100 \%$ & $0 \%$ & $0 \%$ \\
\hline \multirow{2}{*}{$\begin{array}{l}\text { Kigali Institute of Science \& } \\
\text { Technology - Rwanda }\end{array}$} & Diploma & 0 & 0 & 0 & - & - & $8 \%$ \\
\cline { 2 - 9 } & Degree & 13 & 23 & 1 & $42 \%$ & $24 \%$ & $34 \%$ \\
\cline { 2 - 9 } & Diploma & 3 & 2 & 0 & $71 \%$ & $29 \%$ & $0 \%$ \\
\hline
\end{tabular}

Table 2: Number of AVU-Curtin Students Graduating from Degree and Diploma Business Courses 2007 2009 